\title{
PENGARUH HARGA PAKAN DAN UPAH TENAGA KERJA TERHADAP USAHA TERNAK SAPI POTONG PETANI PETERNAK DI DESA WINERU KECAMATAN LIKUPANG TIMUR KABUPATEN MINAHASA UTARA
}

\author{
Ricky S. Otampi , F. H. Elly*, M. A. Manese, G. D. Lenzun \\ Fakultas Peternakan Universitas Sam Ratulangi Manado, 95115
}

\begin{abstract}
ABSTRAK
Perkembangan usaha sapi potong memberikan dampak positif terhadap pembangunan ekonomi. Usaha sapi potong dapat meningkatkan pendapatan petani peternak, menyediakan bahan pangan hewani, menyediakan bahan baku berbagai industri dan membuka lapangan kerja terutama di daerah-daerah sentra sapi potong. Beberapa permasalahan yang dialami petani peternak yaitu ketersediaan pakan serta sumber daya manusia (SDM). Berdasarkan permasalahan maka telah dilakukan penelitian dengan tujuan menganalisis keuntungan usaha ternak sapi potong dan pengaruh harga pakan dan upah tenaga kerja terhadap keuntungan.Penelitian ini telah dilakukan dengan menggunakan metode survey, dan sumber data adalah data primer.Penentuan sampel telah dilakukan dengan menggunakan metode purposive sampling yaitu berdasarkan pertimbangan bahwa petani peternak yang memiliki ternak sapi minimal 2 ekor dan pernah menjual ternak sapi. Analisis data yaitu menggunakan analisis deskriptif dan fungsi keuntungan unit output price. Hasil penelitian menunjukkan bahwa jumlah ternak sapi yang dimiliki sebanyak 83 ekor dengan jumlah ternak sapi yang terjual 43 ekor.Pakan yang dikonsumsi adalah limbah jagung dan rumput lapangandengan total
\end{abstract}

*Korespondensi (Corresponding Author)

Email: femi_elly@yahoo.co.id
$12,125 \mathrm{~kg} / \mathrm{ekor} / \mathrm{hari}$. Alokasi jam kerja yang terbesar adalah untuk memindahkan sapi yaitu $48 \%$ untuk ternak sapi yang dimiliki dan 35,84\% untuk ternak sapi terjual. Berdasarkan hasil penelitian dapat disimpulkan bahwa rataan keuntungan usaha sapi potong yang dijalankan oleh petani peternak adalah positif (Rp. 2.692.830). Harga pakan dan upah tenaga kerja memberikan pengaruh yang nyata terhadap keuntungan usaha sapi potong.

Kata Kunci: ternak sapi, harga pakan, upah tenaga kerja, keuntungan

\section{ABSTRACT}

INFLUENCE OF FEED PRICE AND LABOR WAGE TO PROFIT OF CATTLE FARMING IN WINERU VILLAGE EAST LIKUPANG SUB DISTRICT NORTH MINAHASA REGENCY. The development of beef cattle farming has a positive impact on economic development. Beef cattle farming can increase farmers' income, provide animal food, provide raw materials for various industries and create employment, especially in central areas of beef cattle. Some problems that have been experienced by farmers is the availability of feed and human resources. Based on the problem, research has been done to analyze the profit of beef cattle farming and the influence of feed price and labor wage on profit. This research 
has been done by using survey method, and data source is primary data. Determination of the sample has been done by using purposive sampling method, that is based on the consideration that farmers who have cattle at least 2 tails and never sell cattle. Data analysis was done by using descriptive analysis and profit function of output unit price. The results showed that number of cattle owned as many as 83 heads with number of cattle that have sold 43 tails. Feed consumed is corn waste and field grass, with a total of $12.125 \mathrm{~kg} /$ head / day. Allocation of working hours, the largest, is to move cattle ie $48 \%$ for cattle owned, and $35.84 \%$ for cattle sold. Based on the results of research that average profit of beef cattle farming is positive ( $\operatorname{Rp} 2,692,830)$. Price of feed and labor wage significantly influence profit of beef cattle farming.

Keywords: cattle, feed prices, labor wages, profits

\section{PENDAHULUAN}

Perkembangan usaha sapi potong memberikan dampak positif terhadap pembangunan ekonomi. Usaha sapi potong dapat meningkatkan pendapatan petani/peternak, menyediakan bahan pangan hewani, menyediakan bahan baku berbagai industri dan membuka lapangan kerja terutama di daerah-daerah sentra sapi potong. Limbah usaha sapi potong seperti kotoran sapi dan urin pun dapat dimanfaatkan sebagai bahan dasar pembuatan pupuk organik dan biogas.Usaha pembuatan organik dan biogas merupakan suatu motivasi dan strategi dalam penurunan gas rumah kaca (Kim dan Lyon, 2011). Suroyo et al. (2013) meyatakan bahwa salah satu penghasil bahan organik yang tinggi dan kontinyu adalah ternak sapi. Perkembangan usaha sapi potong perlu dilakukan baik dari segi kualitas maupun kuantitas. Perkembangan dari segi kualitas dapat dilihat dari pengelolaan usaha yang baik mulai dari pembibitan atau pemilihan bibit hingga pemasaran produk. Sedangkan perkembangan dari segi kuantitas dapat dilihat dari jumlah usaha yang ada, jumlah kepemilikan ternak hingga omset dari usaha yang dijalankan.Usaha sapi potong di Indonesia baik dari segi kualitas maupun kuantitas masih perlu ditingkatkan lagi. Khusus usaha sapi potong di pedesaan dijalankan oleh petani/peternak secara tradisional dengan kemampuan dan peralatan seadanya. Usaha semacam inilah yang menjadi prioritas pemerintah untuk dikembangkan menjadi usaha yang lebih maju. Usaha sapi potong yang dijalankan secara tradisonal pun tak luput dari berbagai permasalahan. Beberapa permasalahan yang dialami petani/peternak yaitu ketersediaan pakan serta sumber daya manusia (SDM). Lambatnya pertumbuhan populasi dan produksi daging sapi ditentukan oleh faktor eksternal, diantaranya manajemen 
reproduksi (Herianti dan Subuharta, 2013) dan ketersediaan pakan yang tidak mencukup.Pakan sangat diperlukan ternak untuk menunjang kebutuhan nutrisi tubuh dan pada akhirnya meningkatkan pertambahan berat badan sapi. Pada musim kemarau, pakan bernutrisi sulit untuk diperoleh sehingga sapi hanya diberikan pakan seadanya yang dapat diperoleh petani/peternak. Menurut Prawiradiputra (2011), salah satu faktor yang menentukan baik buruknya pertumbuhan ternak sapi adalah pakan yang dikonsumsinya. Permasalahan utama yang sering dihadapi oleh petani peternak sapi berdasarkan beberapa peneliti adalah masalah pakan (Alfian et al., 2012, Nugraha et al., 2013, Rusdiana dan Adawiyah, 2013, Rahmansyah et al., 2013, Susanti et al., 2013). Informasi dari $62 \%$ petani peternak sapi menurut hasil penelitian Hermawan dan Utomo (2013) bahwa faktor pembatas dalam usaha tani ternak sapi adalah tersedianya hijauan pakan. Permasalahan yang lain adalah berkaitan dengan sumber daya manusia yang terlibat dalam pengembangan usaha peternakan sapi. Petani peternak dalam hal ini menggunakan tenaga kerja yang berasal dari anggota keluarga dalam mengelola usaha ternak sapi potong. Pekerjaan yang dilakukan seperti memindahkan, memberi pakan dan memandikan sapi. Fenomena di atas menunjukkan bahwa peternakan sapi potong di daerah penelitian masih dikelola secara tradisional. Hal ini menunjukkan dibutuhkan suatu kebijakan berkaitan dengan beralihnya usaha ternak sapi potong dari tradisional ke arah usaha yang berorientasi bisnis. Kebijakan tersebut dibutuhkan mengingat menurut Suryana (2009) bahwa ternak sapi sebagai ternak penghasil daging terbesar dalam menunjang produksi daging Nasional. Ternak sapi adalah sumberdaya alam yang dapat diperbaharui (renewable) serta memiliki potensi dalam menunjang dinamika ekonomi suatu daerah (Martan, 2012).

Kecamatan Likupang Timur adalah kawasan sentra produksi peternakan dan pertanian di Sulawesi Utara yang tengah dikembangkan untuk menunjang pertumbuhan dan perkembangan sistem usaha peternakan sapi potong. Daerah ini memiliki populasi ternak sapi terbesar di Kabupaten Minahasa Utara yaitu berjumlah 1.908 ekor (BPS Likupang Timur, 2014). Pengembangan usaha sapi potong di daerah ini dilakukan oleh petani peternak masih secara tradisional. Ternak sapi digembalakan di lahan-lahan pertanian dengan cara dipindah-pindahkan dari lahan pertanian yang satu ke lahan pertanian 
lainnya. Pakan yang dikonsumsi ternak sapi adalah limbah pertanian ataupun rumput yang tumbuh liar. Petani peternak, pada waktu tertentu memotong rumput untuk dikonsumsi oleh ternak sapi atau membeli limbah pertanian kepada petani yang lain.

Permasalahan yang lain adalah tenaga kerja yang dialokasikan untuk usaha ternak sapi potong adalah tenaga kerja keluarga. Petani peternak dalam hal ini menyediakan sebagian waktunya untuk mengembangkan ternak sapi. Waktu tenaga kerja tersebut apabila dialokasikan untuk usaha pertanian milik orang lain maka mereka akan memperoleh upah tenaga kerja sebesar upah yang berlaku.

Berdasarkan latar belakang dan permasalahan maka dirumuskan masalah sejauh mana harga pakan dan upah tenaga kerja berpengauh terhadap keuntungan usaha sapi potong. Penelitian ini bertujuan untuk menganalisis pengaruh harga pakan dan upaha tenaga kerja terhadap Keuntungan usaha sapi potong di Desa Wineru, Kecamatan Likupang Timur, Kabupaten Minahasa Utara.

\section{METODE PENELITIAN}

Metode Penentuan data yang dikumpulkan terdiri atas data primer dan sekunder. Data primer diperoleh melalui pengamatan langsung dan wawancara terhadap responden berdasarkan daftar pertanyaan (kuesioner). Sedangkan data sekunder merupakan data yang diperoleh dari Lembaga atau instansi terkait dengan penelitian ini yaitu Dinas Pertanian Peternakan, Kantor Kecamatan / Desa.

Penentuan sampel dilakukan dengan secara purposive Sampling yaitu sampel dipilih berdasarkan pertimbanganpertimbangan tertentu dan berdasarkan tujuan penelitian. Pada penelitian ini sampel dipilih berdasarkan pertimbangan : petani peternak yang memiliki ternak sapi minimal 2 ekor dan pernah menjual ternak sapi.

Definisi variabel dan pengukurannya adalah:(1) Jumlah ternak sapi potong yang dimiliki oleh responden sebagai petani peternak (ekor); (2) Keseluruhan lahan sebagai sumber pakan ternak yang dimiliki oleh responden (Ha); (3) Rumput yang diberikan oleh petani peternak untuk konsumsi ternak sapi potong (kg/tahun); (4) Harga rumput yang dibayar petani untuk membeli rumput yang dikonsumsi ternak sapi (Rp); (5) Jumlah jam kerja yang dilakukan oleh petani peternak dalam usaha ternak sapi potong (jam/hari); (6) Upah yang dibayar petani untuk pekerja usahatani yang disewa berdasarkan upah yang berlaku di 
daerah penelitian (Rp/jam); (7) Penerimaan dihitung berdasarkan jumlah ternak sapi potong yang dijual (Rp/tahun); (8) Biaya produksi, terdiri dari biaya tetap dan biaya variabel. Biaya tetap dihitung berdasarkan biaya-biaya yang sifatnya tetap, seperti biaya kandang dan peralatan. Biaya variabel dihitung berdasarkan biaya-biaya yang sifatnya tidak tetap, seperti biaya pakan dan biaya tenaga kerja (Rp/tahun); (9) Keuntungan dihitung berdasarkan selisih antara penerimaan dan biaya yang dikeluarkan (Rp/tahun).

Data yang diperoleh dari hasil penelitian ditabulasi dan dianalisis dengan menggunakan metode analisis deskriptif dan matematika. Metode analisis deskriptif dapat diartikan sebagai prosedur pemecahan masalah yang diselidiki dengan menggambarkan atau melukiskan keadaan subjek/objek penelitian pada saat sekarang berdasarkan fakta-fakta yang tampak atau sebagaimana adanya. Analisis data untuk menjawab tujuan pertama adalah menggunakan analisis profit. Keuntungan (profit) adalah selisih antara penerimaan $($ Total Revenue $=\mathrm{TR})$ dengan total biaya (Total Cost $=$ TC). Faktor-faktor yang mempengaruhi keuntungan usaha ternak sapi potong dianalisis dengan menggunakan model fungsi keuntungan Unit Output Price (Elly, 2011).

\section{HASIL DAN PEMBAHASAN}

Keberhasilan usaha ternak sapi potong ditentukan oleh karakteristik dari petani peternak sapi potong sebagai responden. Karakteristik responden diantaranya umur dan tingkat pendidikan. Salah satu faktor yang mempengaruhi pengambilan keputusan petani dalam melakukan pengembangan usaha yaitu faktor umur. Umur responden (Tabel 1) memiliki kaitan yang erat dengan kemampuan kerja dan pola pikir petani/peternak dalam menentukan tata laksana usaha yang dijalankan.

Umur produktif yaitu umur pada kisaran 15-64 tahun sedangkan umur nonproduktif yaitu $\geq 65$ tahun.Berdasarkan hasil wawancara, umur responden berada pada kisaran 21-72 tahun. Tabel 1 menunjukkan bahwa responden dengan usia produktif berjumlah 27 orang $(84,38 \%)$ dari total 32 orang responden yang ada. Sebagian besar responden yaitu 12 orang $(37,50 \%)$ berada pada kisaran umur 51-60 tahun. 
Tabel 1. Klasifikasi Responden Berdasarkan Umur

\begin{tabular}{rcrr}
\hline No & $\begin{array}{c}\text { Kelompok Umur } \\
\text { ( Tahun ) }\end{array}$ & $\begin{array}{c}\text { Jumlah Peternak } \\
(\text { Jiwa })\end{array}$ & Persentase (\%) \\
\hline 1 & $21-30$ & 5 & 15,63 \\
2 & $31-40$ & 4 & 12,50 \\
3 & $41-50$ & 6 & 18,75 \\
4 & $51-60$ & 12 & 37,50 \\
5 & $61-70$ & 4 & 12,50 \\
6 & $>70$ & 1 & 3,13 \\
\hline & Jumlah & 32 & 100 \\
\hline
\end{tabular}

Tabel 2. Klasifikasi Responden Berdasarkan Tingkat Pendidikan.

\begin{tabular}{ccrr}
\hline No & Pendidikan & Jumlah Peternak & Persentase (\%) \\
\hline 1 & SD & 17 & 53,13 \\
2 & SMP & 11 & 34,38 \\
3 & SMA & 4 & 12,50 \\
\hline & Jumlah & 32 & 100,00 \\
\hline
\end{tabular}

Kiswanto et al. (2004) menyatakan bahwa makin tinggi umur petani, sampai batas tertentu, maka kemampuan untuk bekerja akan semakin meningkat sehingga produktifitasnya meningkat.

Pendidikan adalah karakteristik petani peternak sebagai responden dalam menentukan keberhasilan usaha ternak sapi potong. Pendidikan dalam hal ini turut berpangaruh terhadap pengambilan keputusan seseorang atau petani peternak dalam melakukan pengembangan usahataninya.Tingkat pendidikan (Tabel 2) dalam usaha tani dapat membantu petani/peternak dalam penerapan teknologi pertanian yang ada.
Tabel 2 menunjukkan bahwa semua responden mengenyam pendidikan di bangku sekolah. Hanya saja sebagian besar responden yaitu 17 orang $(53,13 \%)$ hanya mengenyam pendidikan pada taraf Sekolah Dasar. Pendidikan tertinggi yang ditempuh responden yaitu SMA dan hanya 4 orang $(12,50 \%)$ responden yang menempuh pendidikan pada tingkat ini

Kiswanto et al. (2004) menyatakan bahwa makin tinggi tingkat pendidikan formal petani, makin rasional pola pikir dan daya nalarnya. 
Tabel 3. Rata-rata Konsumsi Limbah Jagung dan Rumput Lapangan oleh Ternak Sapi

\begin{tabular}{|c|c|c|c|}
\hline No & Rumput & $\begin{array}{c}\text { Jumlah Konsumsi } \\
\text { (Kg/Ekor/Hari) }\end{array}$ & Persentase $(\%)$ \\
\hline 1 & Limbah Jagung & 6,5625 & 54,02 \\
\hline \multirow[t]{2}{*}{2} & Rumput Lapangan & 5,5625 & 45,88 \\
\hline & Total & 12,1250 & 100,00 \\
\hline \multicolumn{2}{|c|}{ Totak konsumsi rumput (Kg/Ekor/Tahun) } & $4.425,625$ & \\
\hline
\end{tabular}

Jumlah ternak sapi milik petani peternak sebagai responden sebanyak 83 ekor dengan pemilikan untuk masing-masing sebanyak 24 ekor (atau rata-rata 2,59 ekor per petani peternak). Pemilikan ternak sapi potong oleh petani peternak menunjukkan sistem pemeliharaan ternak masih tradisional.Hal ini seperti dikemukakan Nurcholida et al. (2013) bahwa 90\% usaha ternak sapi dilaksanakan secara tradisional. Usaha ternak sapi yang demikian dikategorikan sebagai peternakan rakyat. Pakan (Tabel 3) yang diberikan untuk ternak sapi yang dimiliki petani peternak adalah berupa limbah pertanian (jerami jagung) dan rumput lapangan.

Data pada Tabel 3 menunjukkan bahwa jumlah limbah jagung yang dikonsumsi ternak sapi lebih banyak $(54,02 \%)$ dibanding rumput lapangan.
Nurdiati et al. (2012) mengemukakan bahwa pengembangan ternak sapi rakyat dilakukan dengan memanfaatkan limbah pertanian. Menurut Gupta et al. (2012), produk limbah dari satu komponen berfungsi sebagai sumberdaya untuk komponen yang lain. Total konsumsi sesuai Tabel 1 sebanyak $12,1250 \mathrm{~kg} / \mathrm{ekor} / \mathrm{hari}$. Jumlah ini dianggap belum memenuhi standar seperti yang dianjurkan.Padahal pakan ternak sapi menurut Gunawan et al. (2013), Lamid et al. (2014) dan Saragi (2014) adalah faktor penting dalam mengembangkan ternak sapi. Standar/norma kebutuhan hijauan makanan ternak per ekor per hari berdasarkan Satuan Ternak Sapi adalah: ternak dewasa (1 ST) memerlukan pakan hijauan sebanyak $35 \mathrm{~kg}$, ternak muda (0.50 ST) sebanyak $15-17.5 \mathrm{~kg}$ dan anak ternak (0.25 ST) sebanyak 7.5-9 kg/ekor/hari (Kementerian Pertanian, 2010). 
Tabel 4. Rata-rata Biaya Rumput yang Dikeluarkan oleh Petani Peternak untuk Ternak Sapi Yang Dimiliki dan Sapi Terjual

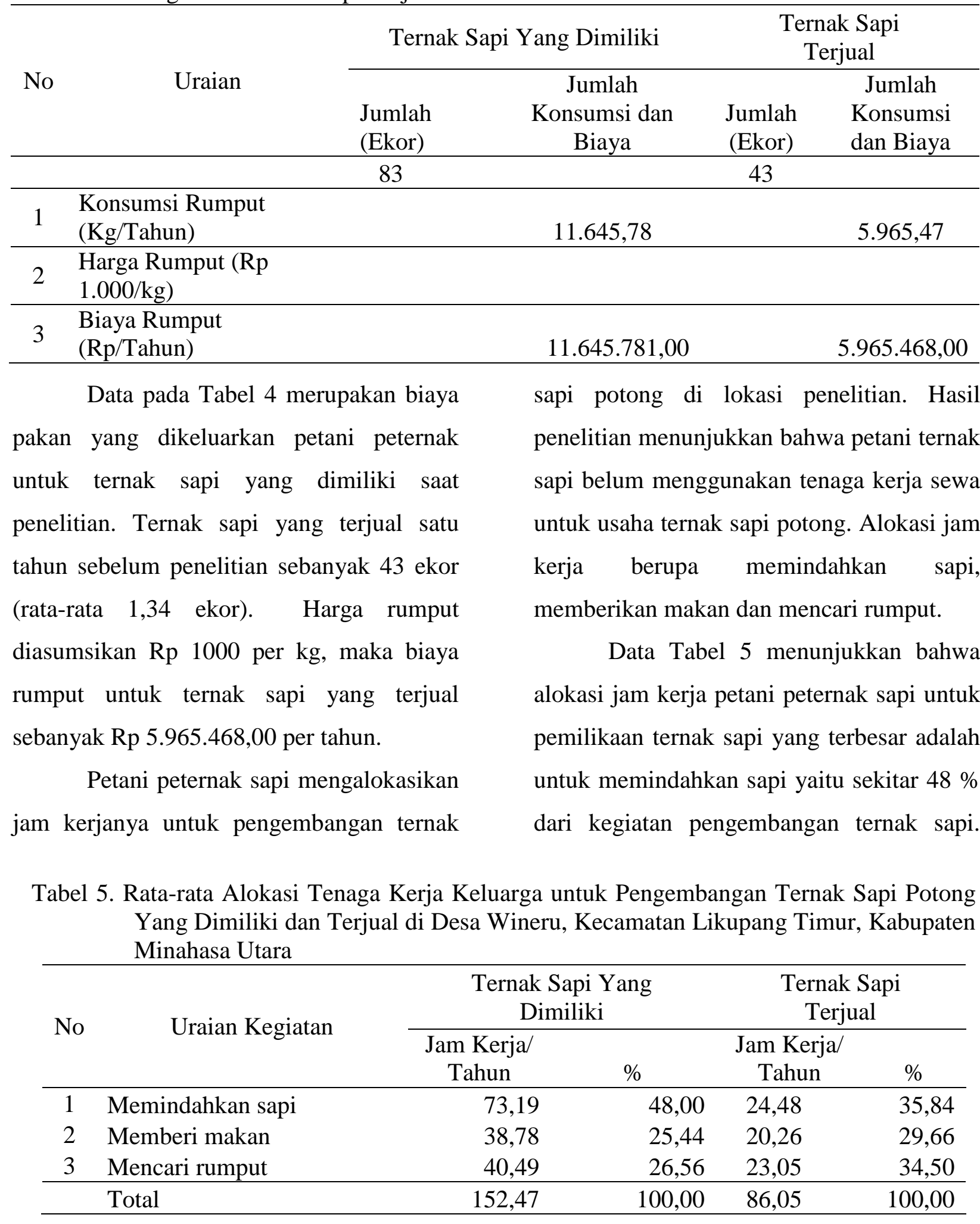


Tabel 6. Rata-rata Biaya Tenaga Kerja yang Dikeluarkan oleh Petani Peternak untuk Ternak Sapi Yang Dimiliki dan Sapi Terjual.

\begin{tabular}{|c|c|c|c|c|c|}
\hline \multirow{4}{*}{ No } & \multirow{4}{*}{ Uraian } & \multicolumn{2}{|c|}{$\begin{array}{c}\text { Ternak Sapi Yang } \\
\text { Dimiliki }\end{array}$} & \multicolumn{2}{|c|}{$\begin{array}{l}\text { Ternak Sapi } \\
\text { Terjual }\end{array}$} \\
\hline & & \multicolumn{3}{|c|}{ Jumlah Jam } & \multirow{3}{*}{$\begin{array}{c}\text { Jumlah Jam } \\
\text { Kerja dan } \\
\text { Biaya TK } \\
\end{array}$} \\
\hline & & Jumlah & Kerja dan & Jumlah & \\
\hline & & (Ekor) & Biaya TK & (Ekor) & \\
\hline & & 83 & & 43 & \\
\hline 1 & Jam Kerja/Tahun & & 152,46 & & 86,05 \\
\hline 2 & $\begin{array}{l}\text { Upah Tenaga Kerja (Rp } \\
\text { 9375/jam) }\end{array}$ & & & & \\
\hline 3 & $\begin{array}{l}\text { Biaya Tenaga Kerja } \\
\text { (Rp/Tahun) }\end{array}$ & & $1.429 .346,00$ & & $229.461,70$ \\
\hline
\end{tabular}

Hal ini disebabkan karena petani peternak sapi memindahkan ternak sapi dua kali sehari.

Jumlah alokasi waktu tergantung jarak yang ditempuh petani peternak sapi dari lokasi yang satu ke lokasi lainnya. Petani peternak juga mencari rumput dengan alokasi jam 26,56 \% dari kegiatan pengembangan ternak sapi. Peternak peternak sapi menyiapkan waktunya mencari rumput untuk kebutuhan konsumsi ternak sapi pada malam hari.Hal ini disebabkan karena ternak sapi pada malam hari diikat di dekat rumah dari petani peternak sapi. Alokasi jam kerja petani peternak sapi untuk ternak sapi yang terjual, memindahkan sapi juga merupakan alokasi terbesar $(35,84 \%$ dari kegiatan pengembangan ternak sapi). Tenaga kerja keluarga yang digunakan dalam usaha ternak sapi dihitung dalam bentuk biaya apabila tenaga kerja mereka dialokasikan untuk usahatani orang lain. Rata-rata biaya tenaga kerja untuk ternak sapi yang dimiliki oleh petani peternak sapi potong dan ternak sapi terjual dapat dilihat pada Tabel 6.

Data pada Tabel 6 menunjukkan bahwa rata-rata jam kerja yang dialokasikan untuk ternak sapi yang dimiliki sebesar 152,46 jam per tahun. Rata-rata jam kerja yang dialokasikan untuk ternak sapi yang terjual sebesar 86,05 jam per tahun. Ratarata biaya tenaga kerja yang dikeluarkan oleh petani sebesar Rp 1.429.346 per tahun untuk ternak sapi yang dimiliki saat penelitian.Rata-rata biaya tenaga kerja untuk ternak sapi sebesar Rp. 229.461,70.Biaya tersebut dianalisis dengan upah yang diasumsikan Rp 9.375 per jam atau Rp 75.000 per hari. 
Tabel 7. Rata-rata Biaya Produksi yang Dikeluarkan oleh Petani Peternak untuk Ternak Sapi Yang Dimiliki dan Sapi Terjual di Desa Wineru, Kecamatan Likupang Timur, Kabupaten Minahasa Utara

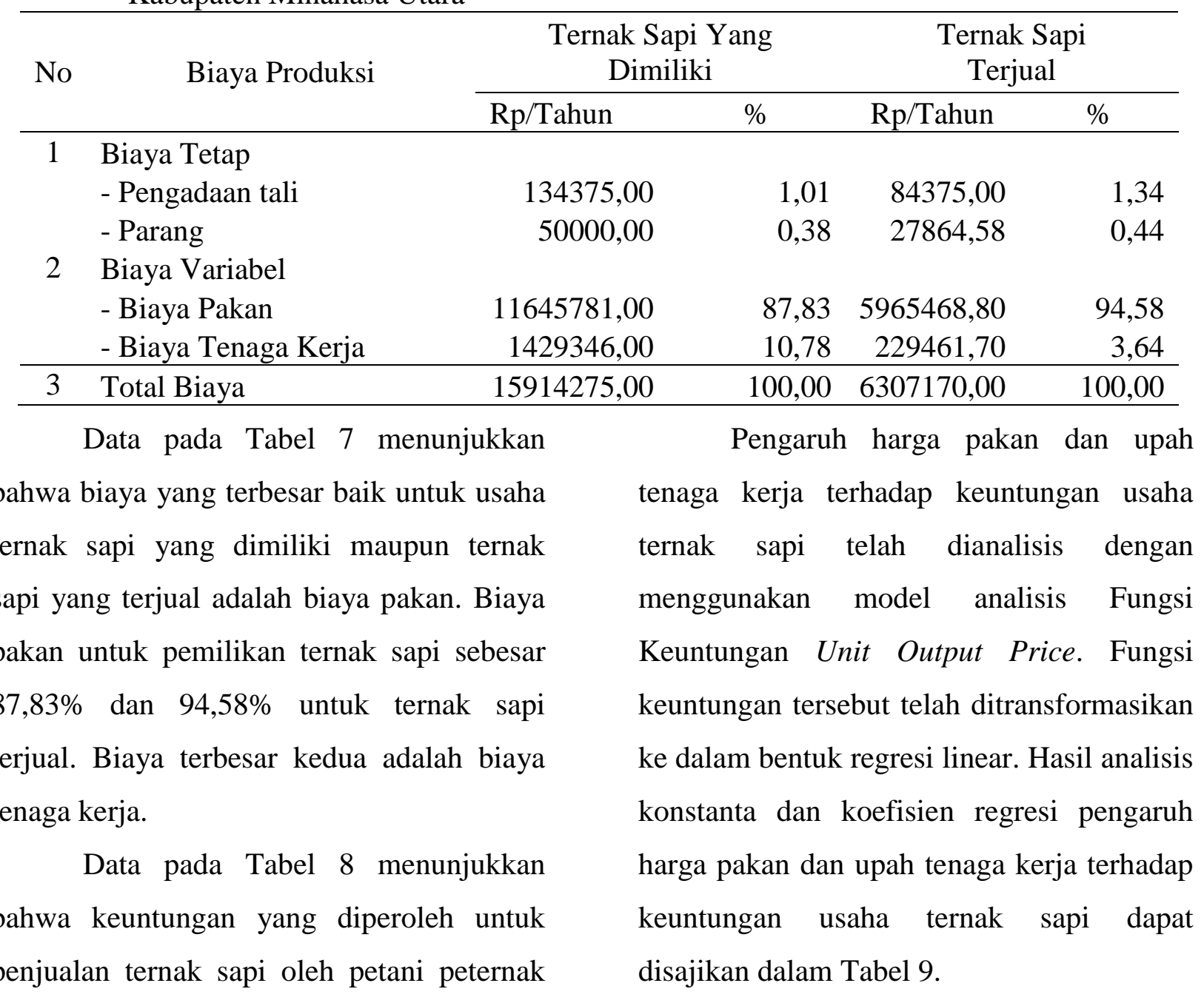
sapi adalah positif. Hal ini ditunjang dengan nilai $\mathrm{R} / \mathrm{C}$ lebih besar dari satu $(1,43)$.

Tabel 8. Rata-rata Penerimaan, Biaya Produksi dan Keuntungan oleh Petani Peternak untuk Ternak Sapi Yang Terjual

\begin{tabular}{llr}
\hline \multicolumn{1}{c}{ Uraian } & \multicolumn{2}{c}{ Total } \\
No $/$ Tahun \\
\hline 1 & Penerimaan Penjualan Sapi & 9.000 .000 \\
2 & Biaya Produksi & 6.307 .170 \\
3 & Keuntungan & 2.692 .830 \\
\hline & R/C & 1,43 \\
\hline & $\pi / \mathrm{C}$ & 0,43 \\
\hline
\end{tabular}


Tabel 9. Konstanta dan Koefisien Regresi

\begin{tabular}{clr}
\hline No & \multicolumn{1}{c}{ Komponen Perhitungan } & Nilai \\
\hline 1 & Konstanta (a) & $-63980,70$ \\
2 & Harga Pakan & $-28591,27$ \\
3 & Upah Tenaga Kerja & 28590,20 \\
\hline
\end{tabular}

Berdasarkan Tabel 9 model analisis regresi secara matematis dapat dituliskan seperti pada persamaan 1 .

$\mathrm{Y}=-63980,70-28591,27 \mathrm{HP}+28590,20$ UTK.

Data pada Tabel 9 menunjukkan bahwa tidak memiliki perubahan harga pakan dan upah tenaga kerja maka keuntungan dimulai dari - 63980,70. Nilai koefisien regresi dari variable harga pakan (HP) sebesar - 28591,27 artinya apabila harga pakan naik Rp 1, maka keuntungan menurun sebesar $\operatorname{Rp} 28.591,27$ ceteris paribus (upah tenaga kerja dianggap konstan).

Nilai koefisien regresi dari variable upah tenaga kerja (UTK) sebesar 28590,20 artinya apabila upah tenaga kerja naik Rp 1, maka keuntungan naik sebesar Rp 28.590,20, ceteris paribus (harga pakan dianggap konstan). Hasil uji F menunjukkan secara bersama sama harga pakan dan upah tenaga kerja berpengaruh nyata terhadap keuntungan usaha ternak sapi potong petani/peternak pada tingkat kepercayaan $99 \%(\alpha=0,01)$. Hasil uji t untuk variabel harga pakan menunjukan secara parsial harga pakan berpengaruh nyata terhadap keuntungan pada tingkat kepercayaan 95\% $(\alpha=0,05)$. Hasil uji t untuk variabel upah tenaga kerja nenunjukan parsial upah tenaga kerja berpengaruh nyata terhadap keuntungan pada tingkat kepercayaan 95\% $(\alpha=0.05)$.

Nilai koefisien determinasi $\left(\mathrm{R}^{2}\right)$ sebesar 0,68 artinya variasi naik turunnya keuntungan $68 \%$ ditentukan oleh variasi naik turunnya variabel harga pakan (HP) dan upah tenaga kerja (UTK). Sisanya 22\% dipengaruhi atau ditentukan oleh faktor lain yang tidak masuk dalam model analisis.

\section{KESIMPULAN DAN SARAN}

Berdasarkan hasil penelitian dapat disimpulkan bahwa rataan keuntungan usaha sapi potong yang dijalankan oleh petani peternak adalah positif (Rp. 2.692.830),-. Harga pakan dan upah tenaga kerja memberikan pengaruh yang nyata terhadap keuntungan usaha sapi potong di Desa 
Wineru, Kecamatan Likupang Barat, Kabupaten Minahasa Utara.

Berdasarkan hasil penelitian maka disarankan petani peternak perlu meningkatkan kuantitas penjualan dan kemampuan tatalaksana usaha. Pemerintah juga perlu mengambil bagian dalam hal penetapan harga sapi yang tergolong cukup rendah.

\section{DAFTAR PUSTAKA}

Alfian, Y., F..I. Hermansyah., E. Hardayanto., Utoyo dan W.P.S. Suprayogi. 2012. Analisis daya tampung ternak ruminansia pada musim kemarau di daerah pertanian lahan kering Kecamatan Semin Kabupaten Gunung Kidul. Tropical Animal Husbandry, Vol. 1 (1):33-42.

BPS Likupang Timur.2014. Likupang Timur dalam Angka.Statistics of Minahasa Utara Regency.

Elly, F.H. 2011. Ilmu Ekonomi Produksi. Penerbit Unsrat Press, Manado.

Gunawan, E.R., D. Suhendra dan D. Hermanto, 2013. Optimalisasi integrasi sapi, jagung dan rumput laut (pijar) pada teknologi pengolahan pakan ternak berbasis limbah pertanian jagung-rumput laut guna mendukung program bumi sejuta sapi (BSS) di Nusa Tenggara Barat. Buletin Peternakan 37 (3):157-164.

Gupta, V., P.K. Rai and K.S. Risam. 2012. Integrated Crop-Livestock Farming
System: A Strategy for Resource Conservation and Environmental Sustainability. Indian Research Journal of Extention Education, Spacial Issue. Vol.2: 49-54.

Herianti, I dan Subuharta. 2013. Kajian Perbaikan Pakan Pada Induk Sapi Potong Lokal di Peternakan Rakyat Kabupaten Kebumen. Prosiding. Seminar Nasional Peternakan Berkelanjutan. Inovasi Agribisnis Peternakan Untuk Ketahanan Pangan. Fakultas Peternakan Universitas Padjadjaran, Bandung. Hal:121-126.

Hermawan, A dan B. Utomo. 2012. Peran ternak ruminansia dalam pengembangan sistem usahatani konservasi di Lahan Kering DAS Bagian Hulu. Prosiding Seminar Nasional Peternakan Berkelanjutan 4, Inovasi Agribisnis Peternak untuk Ketahanan Pangan. Fakultas Peternakan Universitas Padjadjaran. Bandung.

Kementerian Pertanian. 2010. Peningkatan Nilai Tambah dan Daya Saing Produk Pertanian Dengan Pemberian Insentif Bagi Tumbuhnya Industri Pedesaan. Blue Print. Kementerian Pertanian, Jakarta.

Kim, E-H and T.P. Lyon. 2011. Strategic environmental disclosure: Evidence from the DOE's voluntary greenhouse gas registry.J. Envir Ec \& Manag. 61 (2011), 3 (May) : 311-326.

Lamid, M., T. Nurhajati dan R.S. Wahjuni.2014. Potensi Konsentrat Plus untuk Penggemukan Sapi Potong di Kelompok Ternak Harapan Mulya dan Kelompok Tani Ternak 
Jaya Mulya di Kabupaten BangkalanMadura. Agroveteriner. Vol 3 (1):1-7.

Martan, D. 2012. Rancang bangun model kebijakan pengembangan peternakan sapi potong (Studi Kasus di Sulawesi Selatan). Disertasi. Program Doktor Manajemen agribisnis. IPB, Bogor

Nugraha, B.D., E. Handayanta dan E.T. Rahayu. 2013. Analisis daya tampung (Carrying Capacity) Ternak ruminansia pada musim penghujan di daerah pertanian lahan kering Kecamatan Semin Kabupaten Gunung Kidul. Tropical Animal Husbandry, Vol 2 (1): 34-40.

Nurcholida., Sodiq dan K. Muatip. 2013. Kinerja usaha peternakan sapi potong sebelum dan setelah mengikuti program sarjana membangun desa (SMD) Periode 2008-2012. Jurnal Ilmiah Peternakan 1 (3) : 1183-1191.

Nurdiati, K., E. Handayanta dan Lutojo. 2012. Efisiensi produksi sapi potong pada musim kemarau di peternakan rakyat daerah pertanian lahan kering Kabupaten Gunung Kidul. Tropical Animal Husbandry1(1):52-58.

Prawiradiputra, B. 2011. Pasang Surut Penelitian dan Pengembangan hijauan Pakan Ternak di Indonesia. Balai Penelitian Ternak, Bogor.

Rahmansyah, M., A. Sugiharto., A. Kanti dan I.M. Sudiana.2013. Kesiagaan Pakan pada Ternak Sapi Skala Kecil sebagai Strategi Adopsi Terhadap Perubahan Iklim melalui Pemanfaatan Biodiversitas Flora Lokal. Buletin Peternakan Vol. 37 (2): 95-106.
Rusdiana, S dan C.R. Adawiyah.2013. Analisis Ekonomi dan Prospek Usaha Tanaman dan Ternak Sapi di Lahan Perkebunan Kelapa. SEPA, Vol. 10(1):118-131.

Saragi, M.P. 2014. Potensi dan Kualitas Limbah Pertanian sebagai Pakan di Kabupaten Bandung dan Bogor untuk Pengembangan Budidaya Ternak Sapi Perah. Tesis. Sekolah Pascasarjana, IPB Bogor.

Suroyo., Suntoro dan Suryono. 2013. Sistem tumpangsari dan integrasi ternak terhadap perubahan sifat fisik dan kimia tanah litosol. Sains TanahJurnal Ilmu Tanah dan Agroklimatologi 10 (1) :71-80.

Suryana. 2009. Pengembangan usaha ternak sapi potong berorientasi agribisnis dengan pola kemitraan. Balai Pengkajian Teknologi Pertanian Kalimantan Kabupaten Karangasem. Prosiding Seminar Nasional Inovasi Ipteks Perguruan Tinggi untuk Meningkatkan Kesejahteraan Masyarakat oleh Lembaga Penelitian dan Pemberdayaan Masyarakat (LPPM) Unimas Denpasar Bali, 2930 Agustus 2016.

Susanti, A.E., A. Prabowo dan J. Karman. 2013. Identifikasi dan Pemecahan Masalah Penyediaan Pakan Sapi Dalam Mendukung Usaha Peternakan Rakyat di Sumatera Selatan. Prosiding.Seminar Nasional Peternakan Berkelanjutan. Inovasi Agribisnis Peternakan Untuk Ketahanan Pangan. Fakultas Peternakan Universitas Padjadjaran, Bandung. Hal:127-132. 